\title{
Es ist Zeit, näher zusammenzurücken
}

\author{
Ludwig T. Heuss
}

Prof. Dr. med., Präsident des Verwaltungsrates EMH Schweizerischer Ärzteverlag

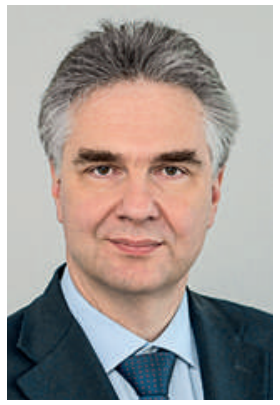

Es ist Ihnen aufgefallen. Mit dieser Ausgabe der Schweizerischen Ärztezeitung halten Sie auch eine neue Fortbildungszeitschrift in den Händen. Die Farben und das Layout erinnern vielleicht an Bekanntes, aber die Sache selbst ist neu: eine Gemeinschaftsproduktion der Redaktionen des Swiss Medical Forum (SMF) und der Revue Médicale Suisse (RMS). Stolz präsentieren sich die beiden Eltern auf dem Titelblatt, und die Zeitschrift braucht sich ihrer Herkunft auch wahrlich nicht zu schämen. Unter der umsichtigen Leitung von Prof. Gérard Waeber aus Lausanne haben sich die beiden führenden medizinischen Fortbildungszeitschriften der Schweiz zusammengetan und ein gemeinsames Heft produziert. Es ist vorerst nur eine einzelne gemeinsame Nummer, der im Herbst eine weitere folgen wird. Doch es ist der erste Schritt in die richtige Richtung.

\section{Eine Kooperation über Sprachgrenzen hinweg.}

Die Ärztekammer hat mit ihrer Entscheidung vom November 2011 eine solche Kooperation über die Sprachgrenzen hinweg angemahnt, und es gibt keinen Grund, sie nicht zu vertiefen. Im Gegenteil. Das Swiss Medical Forum und die Revue Médicale Suisse werden beide von unabhängigen schweizerischen Verlagen im Besitz von Berufsorganisationen, also von Ärzten für Ärzte, gemacht. Der Schweizerische Ärzteverlag EMH ist das Verlagshaus im Mehrheitsbesitz der FMH, das getreu den Zielen unseres Berufsverbandes mit drei Kernprodukten die unabhängige, der Qualität verpflichtete Kommunikation über Themen aus Berufspolitik, Weiter- und Fortbildung und Wissenschaft pflegt. Das Verlagshaus der Revue Médicale Suisse, die Genossenschaft Médecine et Hygiène, ist mit der Société Médicale de la Suisse Romande verbunden. Es ist der gleiche Geist, der beide Unternehmen beseelt, das wird bei einer solchen Zusammenarbeit spürbar - und gewiss nicht nur für uns, sondern auch für Sie, als Leserin oder Leser des Heftes. Aber die Kultur ergänzt sich auch.

Man mag sich angesichts der Internationalität medizinischer Forschung, angesichts von EbM und Internet darüber wundern, aber Sprache, Gesellschaft und

\section{Es ist der gleiche Geist, der die beiden Unternehmen beseelt.}

Unabhängigkeit garantiert. Als Verlage sind wir der schweizerischen Medizin auf der Spur, versuchen wir die Fahne hochzuhalten, auch gegenüber ungleich grösseren global agierenden Pressegiganten. «Zusammenarbeiten ist ein Erfolg», schreiben die beteiligten Redaktoren in ihrem Editorial. Mehr denn je gilt es, Innovationsgeist und Flexibilität an den Tag zu legen und näher zusammenzurücken. Wir vom Schweizerischen Ärzteverlag EMH freuen uns auf eine weitere Intensivierung dieser Kooperation. 